\title{
Cytokine-Induced Monocyte Characteristics in SLE
}

\author{
Zhe Zhang, ${ }^{1}$ Kelly Maurer, ${ }^{2}$ Juan C. Perin, ${ }^{1}$ Li Song, ${ }^{2}$ and Kathleen E. Sullivan ${ }^{2}$ \\ ${ }^{1}$ The Center for Bioinformatics, The Children's Hospital of Philadelphia, 34th Street and Civic Center Boulevard, \\ Philadelphia, PA 19104, USA \\ ${ }^{2}$ The Division of Allergy Immunology, The Children's Hospital of Philadelphia, 3615 Civic Center Boulevard, \\ Philadelphia, PA 19104, USA
}

Correspondence should be addressed to Kathleen E. Sullivan, sullivak@mail.med.upenn.edu

Received 15 January 2010; Accepted 14 May 2010

Academic Editor: George C. Tsokos

Copyright (c) 2010 Zhe Zhang et al. This is an open access article distributed under the Creative Commons Attribution License, which permits unrestricted use, distribution, and reproduction in any medium, provided the original work is properly cited.

\begin{abstract}
Monocytes in SLE have been described as having aberrant behavior in a number of assays. We examined gene expression and used a genome-wide approach to study the posttranslational histone mark, H4 acetylation, to examine epigenetic changes in SLE monocytes. We compared SLE monocyte gene expression and H4 acetylation with three types of cytokine-treated monocytes to understand which cytokine effects predominated in SLE monocytes. We found that $\gamma$-interferon and $\alpha$-interferon both replicated a broad range of the gene expression changes seen in SLE monocytes. H4 acetylation in SLE monocytes was overall higher than in controls and there was less correlation of H4ac with cytokine-treated cells than when gene expression was compared. A set of chemokine genes had downregulated expression and H4ac. Therefore, there are significant clusters of aberrantly expressed genes in SLE which are strongly associated with altered H4ac, suggesting that these cells have experienced durable changes to their epigenome.
\end{abstract}

\section{Introduction}

Systemic lupus erythematosus (SLE) has long been characterized as a disease associated with the overexpression of proinflammatory cytokines. The early studies focused on proinflammatory genes and identified increased serum levels of TNF $\alpha$, IL-6, $\gamma$ IFN, and IL-10 [1-6]. When cells have been examined directly, either by flow cytometry or culture techniques, $\gamma$ IFN, IL-10, IL-17, and IL- 6 have been found to be increased in SLE patients [7-12]. In contrast, studies have generally supported an underexpression of IL-12, which is classically considered a proinflammatory cytokine $[13,14]$. More recently, studies have identified a signature of type I interferons in whole blood using gene expression arrays [15-19]. This has generated a sea change in the etiologic modeling of the disease and has led to a clinical trial using a neutralizing antibody [20].

Other studies have sought to identify altered expression of chemokines in SLE and these studies have demonstrated increased RANTES, and MCP-1 [21, 22]. Indeed, urine chemokine detection shows promise as an early biomarker of nephritis [23, 24]. Chemokines are often secondary regulators of cell migration, induced by cues from other cells.
This study defined gene expression alterations in monocytes from patients with SLE and correlated those changes with cytokine-induced gene expression changes. We further evaluated $\mathrm{H} 4$ acetylation (H4ac) changes, as $\mathrm{H} 4 \mathrm{ac}$ is an epigenetic mark of transcriptional potential $[25,26]$. Monocytes were selected for study because monocytes and their tissue counterpart, the macrophage, play an extremely important role in systemic lupus erythematosus (SLE). Macrophage infiltration into end organs is thought to be critical to the disease process and renal infiltration of macrophages is specifically associated with a poor prognosis [27]. Monocyte infiltration into glomeruli is driven by fractalkine and both fractalkine levels and monocyte numbers in glomeruli correlate with BUN, proteinuria, and GFR [28]. Additionally, increased macrophage migration inhibitory factor levels correlate with disease activity in lupus patients [29]. Additional well-characterized roles for monocytes in SLE include the clearance of apoptotic cells, participation in atheroma formation, and the elaboration of inflammatory cytokines [30-37].

Monocytes have long been recognized as exhibiting aberrant behavior in patients with systemic lupus erythematosus 


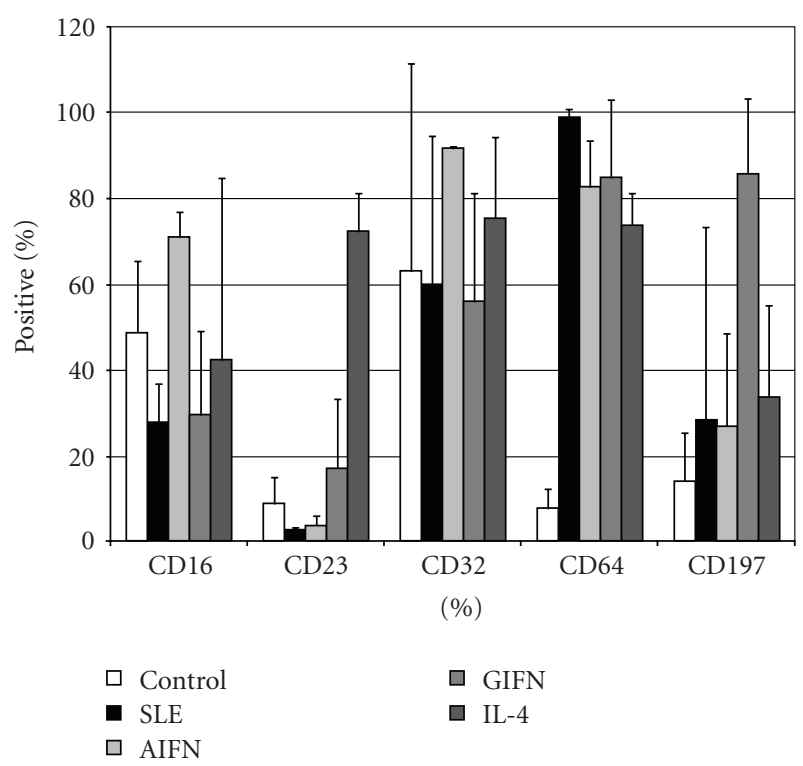

FIGURE 1: Cell surface markers are altered in SLE and cytokine-treated monocytes. Control monocytes were either mock treated or treated with the indicated cytokines for 18 hours $(n=3)$. The SLE cells were studied without any intervention $(n=4)$. In each case, the cells were gated on physical parameters and CD14 expression. The SLE monocytes have statistically significant different expression of CD16 compared to the $\alpha$ IFN-treated cells.

(SLE) [38-42]. The behavior has been variously ascribed to the presence of cytokines, the presence of immune complexes, or inherited polymorphisms, which collectively alter the cells' behavior. The literature on monocytes in SLE is consistent in demonstrating that the monocytes have compromised viability $[36,43]$ have an altered capacity to develop into dendritic cells (DC) $[37,44,45]$ and have compromised uptake of apoptotic debris [46-49]. STAT 1 is phosphorylated in monocytes of patients with SLE and cells have upregulated MHC class I $[15,50]$, consistent with a monocyte response to type I interferons in SLE [16, 17, 19, 51-53].

Patients with SLE have mildly altered monocytes as defined by cell surface markers $[54,55]$, however, cytokine expression is clearly aberrant $[56,57]$. SLE monocytes are generally reported to overproduce IL-1RA [58], IL-6 [59, $60]$, and TNF $\alpha$ in vitro $[55,61]$, while IL-12 production in both humans and mice is diminished [62-64]. To better define disease effects on SLE monocytes, we examined gene expression changes in purified SLE monocytes and compared those to gene expression changes in control monocytes treated with different cytokines. To determine whether any of the gene expression changes could be mediated by altered chromatin, we examined H4ac, as a mark of transcriptional competence [65-67].

\section{Methods}

2.1. Cells and Reagents. The SLE monocyte gene expression and ChIP-chip data have been previously reported [68]. In both cases, healthy control donors were used to establish the baseline. The samples studied here are five controls and 9 patients. The patients had a very low SLEDAI score (mean score 0.6) and were on no immune suppressive medications at the time other than low dose prednisone. The cytokine-treated monocytes utilized the cells from a single donor for each set of cytokine treatments. The cytokine data were reported initially in a separate study (submitted). The data represent the averages of three different donors. The cells were purified by elutriation and were $\geq 95 \%$ pure by CD14 staining. The cells were treated with $50 \mathrm{ng} / \mathrm{ml}$ of IL-4, $50 \mathrm{ng} / \mathrm{ml}$ of $\gamma$ IFN (R\&D Systems, Minneapolis, MN), or $500 \mathrm{IU} / \mathrm{ml}$ of $\alpha \mathrm{IFN}$ (PBL Interferon Source, Piscataway, NJ) for 18 hours. Flow cytometry for cell surface markers utilized antibodies from BD Pharmingen and were run on a FacsCalibur instrument using appropriate isotype controls.

2.2. Microarray Experiments. The H4ac immunoprecipitation was performed as previously described $[69,70]$. Purified DNA from the immunoprecipitation was amplified, cleaved, and labeled using the GeneChip WT double-stranded DNA terminal labeling kit (Affymetrix, Santa Clara, CA). DNA preparation and hybridization were all performed according to the recommendations for the GeneChip Human Promoter 1.0R array (Affymetrix). The U133A 2.0 platform was used for the expression analyses. cRNA was prepared according to the recommendations of the manufacturer (Affymetrix). The expression experiments included nine SLE patients, five healthy controls, and three samples of each cytokine treatment group. The H4ac experiments included four nonspecific GST controls, six patients, five healthy controls, and three samples of each treatment group. The data processing has been previously described for the coanalysis of expression and $\mathrm{H} 4$ acetylation data [68]. Additional information about the data processing and statistical methods is available in the Supplemental Methods.

\section{Results}

3.1. SLE Monocytes Exhibit Cell Surface Marker Expression Which Cannot Be Attributed to Single Cytokine Effect. To understand the biology of monocytes from SLE patients, we examined cell surface markers by flow cytometry. We selected a variety of cell surface markers which have been implicated in monocyte function. The cells were gated on physical parameters and CD14. CD16, CD23, CD32, CD64, CD80, CD197, CD206, and CCR2 expression levels were compared between SLE monocytes and control monocytes treated for 18 hours with cytokines. Cell surface markers significantly altered in SLE are shown in Figure 1. $\gamma$ IFN treatment was associated with increased expression of Fc $\gamma$ RI (CD64) and CCR7 (CD197). IL-4 treatment was associated with increased expression of FceRII (CD23) and the macrophage mannose receptor (CD206). The monocytes polarized with $\alpha$ IFN displayed a unique phenotype with increased CD64. CD80 expression was not significantly altered by any treatment. The SLE monocytes expressed cell surface markers are somewhat consistent with the monocytes treated for 


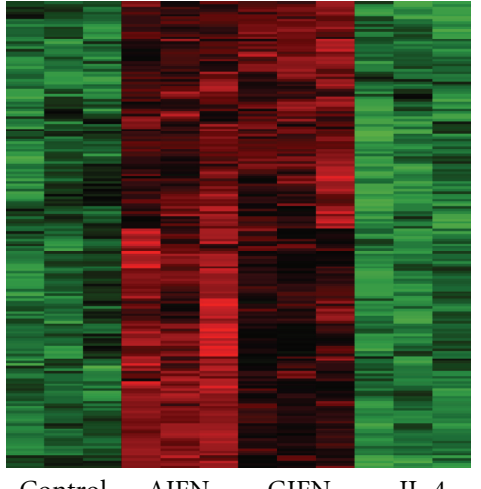

Control AIFN GIFN

\begin{tabular}{|c|c|c|c|}
\hline 2.29 & 1.49 & 1.88 & 1.72 \\
\hline 1.79 & 1.2 & 1.24 & 1.39 \\
\hline 2.33 & 2.7 & 2.67 & 3.67 \\
\hline 1.93 & 0.9 & 0.83 & 1.36 \\
\hline 3 & 1.73 & 2.04 & 2.13 \\
\hline 2.32 & 1.76 & 1.43 & 1.82 \\
\hline 1.77 & 0.37 & 1.67 & 1.46 \\
\hline 2.17 & 1.87 & 2.28 & 1.97 \\
\hline 1.87 & 1.95 & 1.8 & 2.62 \\
\hline 2.11 & 0.91 & 0.7 & 0.75 \\
\hline 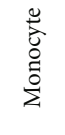 & $\begin{array}{l}\bar{\Xi} \\
\stackrel{\Xi}{ } \\
\ddot{G}\end{array}$ & $\begin{array}{l}\overline{\tilde{U}} \\
\infty \\
\stackrel{\infty}{\sigma} \\
\overrightarrow{0}\end{array}$ & $\begin{array}{l}\frac{\pi}{0} \\
\frac{0}{0} \\
\frac{0}{\Sigma}\end{array}$ \\
\hline
\end{tabular}

SLE versus healthy control

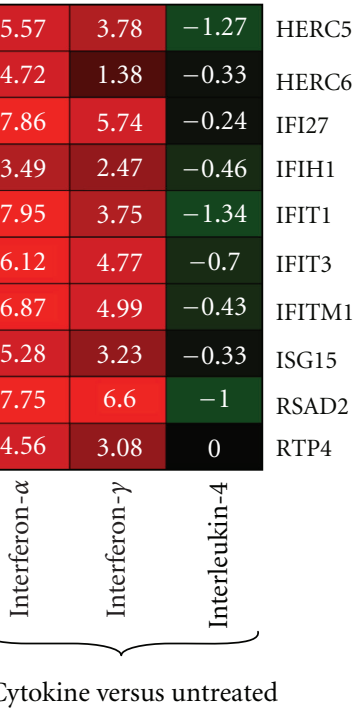

(b)

FIGURE 2: Cluster analysis of genes upregulated by interferons. (a) A subset of genes identified by unbiased clustering analysis were responsive to both $\gamma$ IFN and $\alpha$ IFN, but not IL-4. On average, the expression of these genes was upregulated by $36.3 \%$ in SLE. (b) Ten focus genes identified as being upregulated in four cell types in SLE were examined in the cytokine-treated cells. These genes also exhibited increased expression after $\gamma$ IFN and $\alpha$ IFN treatment but not IL-4 treatment.

18 hours with $\alpha$ IFN, but with a clear difference in CD16 expression. Although in vitro treatment with cytokines does not perfectly replicate chronic in vivo exposure, these data suggested that the phenotype could not be attributed to a single cytokine exposure. We wished to examine whether cytokines could be molding the phenotype of SLE monocytes more globally. With multiple reports of elevated cytokines in addition to type I interferons, we hypothesized that we would find footprints of other cytokine effects within the monocyte population.

\subsection{Overlap between Cytokine-Induced Gene Expression and} the SLE Gene Expression. We performed pairwise comparisons of gene expression between SLE monocytes or cytokine-treated monocytes and healthy or untreated control samples. We filtered the genes with $P$ values $(t$ test $)<.05$ and selected the top 200 genes with the highest or lowest $\log 2$ ratio of group means for further study. According to a permutation procedure, the false discovery rates of genes up- and down-regulated in SLE were 3.1\% and 6.9\%, respectively. To gain insights into the biological alterations as a result of these gene expression changes, we further performed Gene Ontology (GO) analysis through DAVID functional annotation [71]. Table 1 summarizes the top five nonredundant GO terms enriched in SLE or cytokine upregulated genes. The $\alpha$ IFN and $\gamma$ IFN GO terms were similar and partly overlaped the SLE terms, indicating that the SLE monocytes underwent some gene expression changes similar to the effect of interferon treatment. On the other hand, IL-4 terms had little similarity to SLE and interferon terms. This as expected because Il-4 has not been implicated in SLE and was included as a control.
As interferons and IL-4 caused distinctive gene expression changes in monocytes, we carried out a gene clustering analysis on the cytokine data to identify a cluster of 187 genes that responded to both interferons, but not IL-4 (Figure 2(a)). In this cluster, DAVID analysis confirmed the enrichment of genes involved in immune system processes in this cluster $(P=1.4 e-20)$ and identified seven genes with a known relationship to SLE: FAS, CFB, CCR5, CD80, TRIM21, TAP1, and TAP2. The whole cluster was generally upregulated in SLE $(P=3.4 e-14)$ with an average increase of $36.3 \%$. Further investigation of this gene cluster could reveal more details about the unique roles of interferons in SLE.

We also compared our SLE data with those of an independent study, in which purified CD4 T cells, CD19 B cells, and myeloid cells from patients with SLE were used as sources for gene expression arrays [72]. The raw data from the study were downloaded from the GEO database (GSE10325) and processed with the same procedure used in this study. The top 200 upregulated genes were identified with the same criteria from each cell type and ten of them were included in the lists of all cell types examined, including our SLE monocytes. These ten genes were also highly induced by $\alpha$ IFN with a smaller effect seen in the $\gamma$ IFN-treated cells, but slightly down-regulated by IL-4 (Figure 2(b)). This analysis ensured that although our sample population had very low disease activity, the findings were generalizeable.

3.3. H4 Acetylation in SLE. We have previously reported that H4ac was altered in SLE monocytes $[68,73]$. We therefore reanalyzed the data to understand the role of the different cytokines in the altered H4ac landscape of the cells. The 


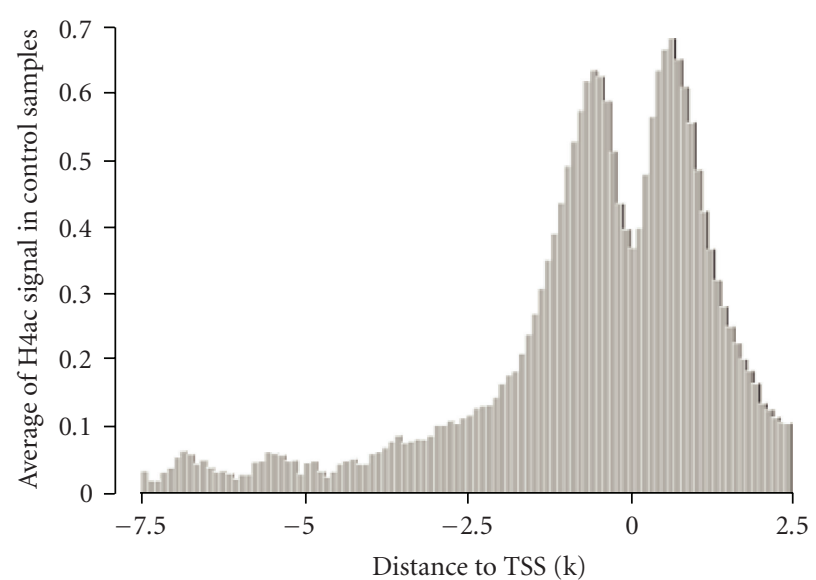

(a)

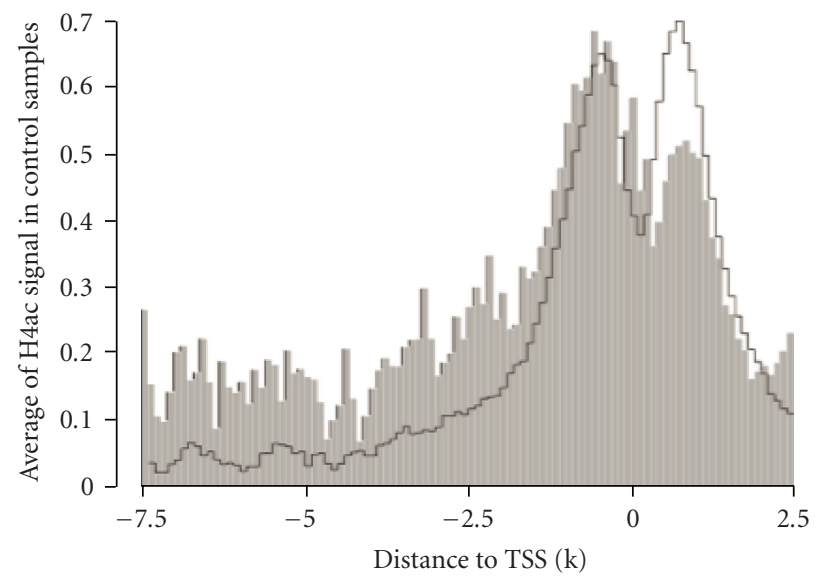

(c)

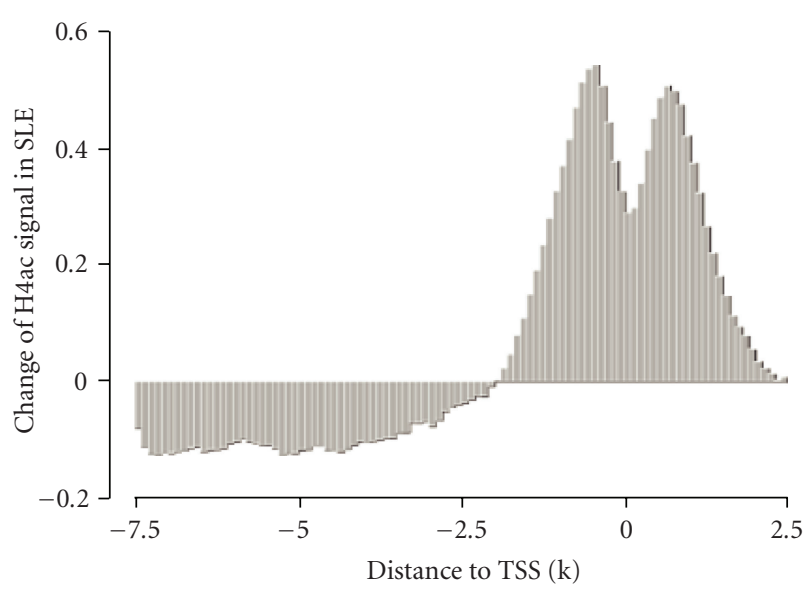

(b)

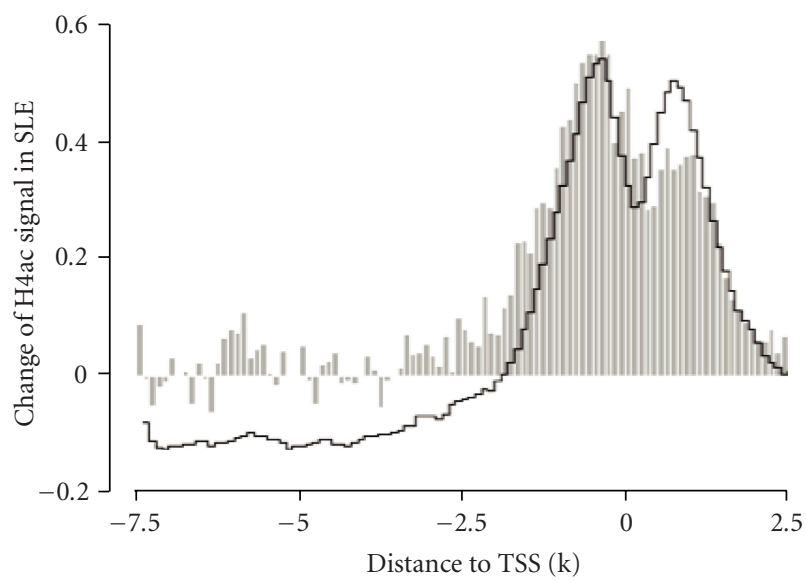

(d)

FIGURE 3: The distribution of H4ac at the promoter. (a) H4ac was distributed around the transcription start site. (b) The SLE monocytes had increased H4ac globally around the transcription start site. (c) The average of H4ac at potential TFBSs (grey area) was different from the general pattern of H4ac around TSS (black line), most notably, it was higher in the promoter region, but lower immediately after the TSSs. (d). In SLE, the average change of H4ac at potential TFBS (grey area) was also different from the general pattern (black line).

H4ac mark was mapped using tiling arrays and all genes were aligned by their transcription start site (TSS). The H4ac content exhibits a forked peak pattern, centered on the TSS (Figure 3(a)) [66, 74]. When the SLE H4ac signal across the genome was compared to controls, SLE genes overall has a higher signal. Much of the difference between the patients and controls lies around the transcription start site, with relative hypoacetylation distant from the TSS (Figure 3(b)). H4 acetylation marks are typically placed by histone acetyltransferases recruited by transcription factors. We previously reported an increase of $\mathrm{H} 4 \mathrm{ac}$ at potential binding sites of transcription factors like IRF1 and the expression change of IRF1-downstream targets [68]. We generalized our analysis in this study. All potential TFBSs in human genome conserved in human/mouse/rat alignment were downloaded from UCSC Genome Browser and mapped to the TSSs. The average H4ac at binding sites around TSSs had a distinctive pattern (Figure 3(c)). TFBSs located in the upstream promoter region had higher H4ac than average while those located immediately downstream of
TSS had lower H4ac content. In SLE monocytes, the H4ac change at TFBSs had a similar pattern (Figure 3(d)). These observations suggest that H4ac at TFBSs is part of an expression regulatory network.

We considered whether increased competence for expression of the histone genes themselves could contribute to this picture. It may be seen that the $\mathrm{H} 4 \mathrm{ac}$ at the $\mathrm{H} 2, \mathrm{H} 3$, and H4 gene clusters was generally increased in SLE monocytes (Figure 4). This could contribute to globally increased H4ac in the SLE monocytes but cannot be the complete explanation because the acetyl mark is placed posttranscriptionally. To understand whether histone acetyltransferases might have dysregulated expression as a mechanism to explain the globally increased $\mathrm{H} 4 \mathrm{ac}$, we examined the expression of the human histone acetyltransferases in SLE patients. The expression of these genes was not globally increased although several individual members were upregulated including HAT1 $(\log 2$ ratio $=0.79)$, KAT2B $(\log 2$ ratio $=0.77)$, MYST3 $(\log 2$ ratio $=0.74)$, and MYST4 $(\log 2$ ratio $=0.53)$. We examined whether this effect was replicated in any of the 
TABLE 1: DAVID analysis of SLE gene expression.

\begin{tabular}{|c|c|c|c|c|}
\hline Gene List & GO Term & Count & $P$ value & Fold Enriched \\
\hline \multirow{5}{*}{ SLE UP } & Immune system process & 45 & $6.46 \mathrm{E}-15$ & 3.78 \\
\hline & Leukocyte activation & 14 & $9.91 \mathrm{E}-06$ & 4.60 \\
\hline & Cytokine receptor activity & 5 & $1.11 \mathrm{E}-03$ & 10.67 \\
\hline & Intracellular signaling cascade & 32 & $3.73 \mathrm{E}-03$ & 1.68 \\
\hline & Defense response & 15 & $2.16 \mathrm{E}-02$ & 1.94 \\
\hline \multirow{5}{*}{ AIFN UP } & Immune system process & 57 & $2.34 \mathrm{E}-23$ & 4.59 \\
\hline & Response to virus & 24 & $4.02 \mathrm{E}-22$ & 16.68 \\
\hline & Defense response & 33 & $1.14 \mathrm{E}-11$ & 4.09 \\
\hline & Induction of apoptosis & 10 & $5.04 \mathrm{E}-03$ & 3.08 \\
\hline & Interferon type I production & 3 & $7.90 \mathrm{E}-03$ & 21.38 \\
\hline \multirow{5}{*}{ GIFN UP } & Immune system process & 63 & $2.08 \mathrm{E}-28$ & 5.04 \\
\hline & Response to virus & 17 & $5.98 \mathrm{E}-13$ & 11.75 \\
\hline & Defense response & 34 & $2.62 \mathrm{E}-12$ & 4.19 \\
\hline & Regulation of apoptosis & 20 & $4.35 \mathrm{E}-04$ & 2.46 \\
\hline & Lymphocyte proliferation & 7 & $6.09 \mathrm{E}-04$ & 6.61 \\
\hline \multirow{5}{*}{ IL4 UP } & Response to external stimulus & 25 & $2.83 \mathrm{E}-05$ & 2.59 \\
\hline & Ribosome biogenesis and assembly & 8 & $3.25 \mathrm{E}-04$ & 6.05 \\
\hline & Cell communication & 72 & $3.46 \mathrm{E}-04$ & 1.43 \\
\hline & Chemokine activity & 6 & $5.24 \mathrm{E}-04$ & 8.85 \\
\hline & Lymphocyte proliferation & 6 & 4.13E-03 & 5.60 \\
\hline
\end{tabular}

TABLE 2: DAVID analysis of H4ac gene sets.

\begin{tabular}{|c|c|c|c|c|}
\hline Gene List & GO Term & Count & $P$ value & Fold Enriched \\
\hline \multirow{5}{*}{ SLE UP } & Membrane-bound organelle & 114 & $2.39 \mathrm{E}-06$ & 1.35 \\
\hline & Nucleic acid binding & 62 & $2.07 \mathrm{E}-05$ & 1.65 \\
\hline & Metabolic process & 122 & 7.37E-04 & 1.19 \\
\hline & Chromatin assembly & 6 & $4.56 \mathrm{E}-03$ & 5.44 \\
\hline & Ribosome biogenesis and assembly & 6 & $9.61 \mathrm{E}-03$ & 4.57 \\
\hline \multirow{5}{*}{ AIFN UP } & Response to virus & 13 & $1.10 \mathrm{E}-08$ & 9.16 \\
\hline & Immune system process & 35 & $3.27 \mathrm{E}-08$ & 2.84 \\
\hline & Structural constituent of ribosome & 7 & $6.30 \mathrm{E}-03$ & 4.18 \\
\hline & Defense response & 17 & $9.08 \mathrm{E}-03$ & 2.03 \\
\hline & Interferon type I production & 3 & $1.20 \mathrm{E}-02$ & 17.17 \\
\hline \multirow{5}{*}{ GIFN UP } & Immune system process & 40 & $9.04 \mathrm{E}-11$ & 3.17 \\
\hline & Late endosome & 7 & $6.58 \mathrm{E}-05$ & 9.70 \\
\hline & Defense response & 22 & $1.13 \mathrm{E}-04$ & 2.56 \\
\hline & Response to virus & 8 & $5.58 \mathrm{E}-04$ & 5.50 \\
\hline & Adaptive immune response & 6 & $5.73 \mathrm{E}-03$ & 5.16 \\
\hline \multirow{5}{*}{ IL4 UP } & Antigen processing and presentation & 7 & $2.08 \mathrm{E}-04$ & 7.96 \\
\hline & Immune system process & 23 & $4.08 \mathrm{E}-03$ & 1.90 \\
\hline & Regulation of protein metabolic process & 11 & $8.14 \mathrm{E}-03$ & 2.66 \\
\hline & Structural molecule activity & 17 & $2.69 \mathrm{E}-02$ & 1.79 \\
\hline & Golgi vesicle transport & 6 & $2.90 \mathrm{E}-02$ & 3.45 \\
\hline
\end{tabular}

cytokine-treated monocytes. Only KAT2B was upregulated in $\gamma$ IFN and $\alpha$ IFN-treated cells, which is consistent with the observation that H4ac is globally elevated in SLE monocytes but not in cytokine-treated cells.

To examine the biological processes anticipated to be altered as a result of the SLE H4ac landscape, we utilized
DAVID for the GO analysis of the 200 genes with the highest H4ac due to cytokine treatment or SLE (Table 2). This strategy collapses the H4ac data into functional categories. In this analysis, the finding of increased H4ac in SLE was seen in processes related to basic cell biology, including basic metabolic processes. Besides the GO terms listed in 


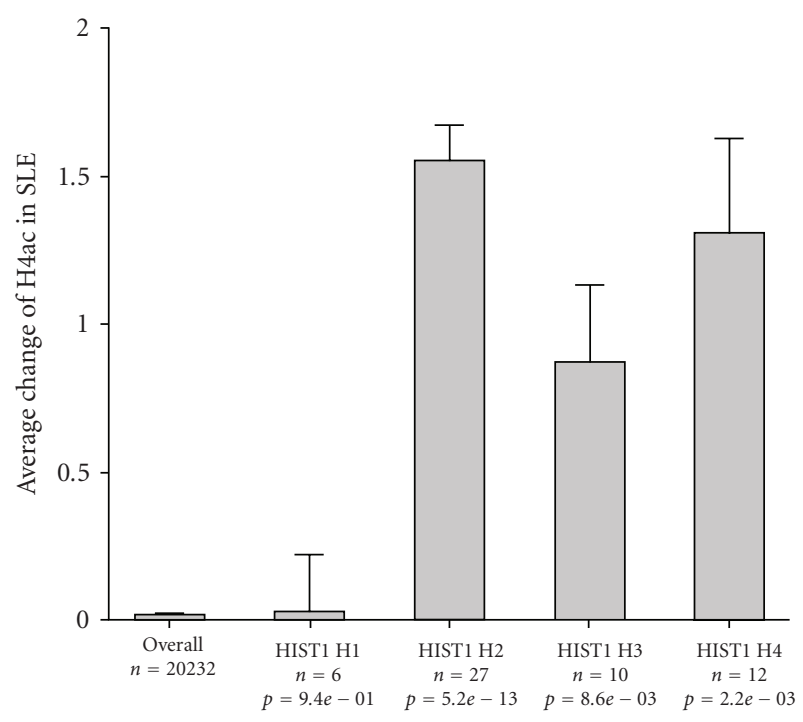

Figure 4: H4ac at histone genes. $\mathrm{H} 2, \mathrm{H} 3$, and $\mathrm{H} 4$ gene families had increased H4ac in SLE monocytes.

Table 2, DAVID also found increased H4ac of the Kruppelassociated box (KRAB) family of transcriptional repressors in SLE monocytes $(P=8.1 e-9)$. These typically function in hematopoietic cell differentiation [75]. When DAVID was used to examine the inferred biological processes altered in SLE compared to those in $\gamma$ IFN and $\alpha$ IFN-treated cells, there was little overlap, suggesting that the SLE monocytes are more fundamentally altered than can be explained by brief cytokine exposure.

3.4. Coanalysis of H4ac and Gene Expression. To understand whether cytokines could alter the chromatin landscape of monocytes and to correlate the H4ac changes seen in SLE monocytes with those induced by cytokines, we examined the agreement between H4ac and expression data of 9553 unique genes measured by both array platforms and the results are summarized in Table 3. The first part of Table 3 (with GST controls) compares the absolute measurements of expression and H4ac in six sample groups, after the GST control was used to remove nonspecific array signals from the H4ac data. The global correlation between expression and $\mathrm{H} 4 \mathrm{ac}$ was consistently around 0.4 in all groups. We picked the 200 top and bottom genes from each group based on their expression and H4ac level and checked the overlap between the two lists. The numbers of overlapped genes and the odds ratios calculated by Fisher's test are also listed in Table 3. The genes with high expression had relatively less overlap with genes with high H4ac, compared to the down-regulated pair, suggesting that high $\mathrm{H} 4 \mathrm{ac}$ is not sufficient to ensure high gene expression. The overlapping at the lower end was much more prominent. The second part of Table 3 (the last four lines) presents the same results based on the relative change of expression and $\mathrm{H} 4 \mathrm{ac}$ within each experimental group. The relative change in expression was calculated from the reference for each group, given in the second column. The global expression-H4ac correlation was notably lower as most genes were not affected by SLE or cytokine treatment. The overlap between genes with increased expression and $\mathrm{H} 4 \mathrm{ac}$ was more significant, especially genes responding to interferons.

We identified two clusters of genes with an unusually high correlation of $\mathrm{H} 4 \mathrm{ac}$ and gene expression. A cluster of chemokine genes that map to chromosome 4 had markedly repressed expression in SLE and this was associated with a markedly diminished H4ac. Interestingly, these genes were repressed by all three cytokines. These chemokines regulate neutrophil function, monocyte migration, and angiogenesis [76-80]. The interferon-responsive genes had a strong association of H4ac and gene expression in SLE and this was replicated in part by exposure to both types of interferon (Figure 5).

To more directly link gene expression change to histone modification, we summarized the average H4ac change of the genes identified above as differentially expressed in SLE or after cytokine treatment (Figure 6). On average, genes with upregulated expression in SLE had a dramatic increase in $\mathrm{H} 4 \mathrm{ac}$. However, as the H4ac was generally increased in SLE, the H4ac around the TSS of down-regulated genes was also increased slightly although H4ac was notably decreased in upstream promoter region. Genes up- or down-regulated by cytokines had a more consistent $\mathrm{H} 4 \mathrm{ac}$ change. An interesting observation in Figure 6 is that the genes upregulated in SLE seemed to have lower baseline $\mathrm{H} 4 \mathrm{ac}$ by average, suggesting that those genes may be repressed in healthy monocytes.

\section{Discussion}

The concept of an altered epigenome in SLE is an attractive model because the epigenome could contribute to the disease perpetuation by molding pathologic gene expression. One of the best-characterized epigenetic changes in SLE is the hypomethylation of DNA in T cells [81]. This finding is consistent in murine models [82] and more recent studies have linked demethylation of DNA with the drug-induced lupus seen with procainamide and hydralazine $[83,84]$. Induced demethylation alters the expression of a number of genes, which could contribute to the pathophysiology of lupus [85-87].

Several groups have utilized histone deacetylase (HDAC) inhibitors in lupus models in an effort to reregulate aberrant gene expression. Trichostatin (TSA) or the chemically related compound, SAHA, was used to treat MRL/lpr mice [88]. These agents increase $\mathrm{H} 4 \mathrm{ac}$ through inhibition of histone deacetylases. This murine model of SLE is characterized by increased expression of $\gamma$ IFN, IL-12, IL-6, and IL-10. In vitro and in vivo treatment with an HDAC inhibitor decreased RNA and protein levels for all four overexpressed cytokines. In addition, administration of TSA led to less active renal disease [88]. HDAC inhibitors are immunosuppressive in vivo and therefore to better understand the epigenome in SLE, we directly characterized the epigenome in SLE [89]. Our previous study of H4ac in SLE monocytes found that many of the changes could be due to overexpression of the transcription factor IRF1 [68]. In the current study, 


\begin{tabular}{|c|c|c|c|c|c|c|c|c|}
\hline 1.89 & 0.42 & 1.67 & -0.09 & GBP1 & 0.98 & 4.16 & 5.5 & 0.53 \\
\hline-0.05 & 0.43 & 1.24 & 0.57 & GBP2 & -0.07 & 1.64 & 3.31 & -0.46 \\
\hline 0.98 & 1.36 & 0.68 & -0.84 & IFI16 & 1.02 & 2.23 & 1.38 & -0.12 \\
\hline-0.83 & 0.54 & 0.13 & -0.2 & IFI27 & 2.33 & 7.86 & 5.74 & -0.24 \\
\hline-0.51 & -0.32 & -0.09 & -0.33 & IFI30 & -0.34 & 0.2 & 0.04 & -0.07 \\
\hline 0.62 & 0.72 & -0.06 & -0.45 & IFI44 & 1.09 & 5.28 & 3.16 & -0.59 \\
\hline 2.05 & 2.86 & 1.28 & 0.2 & IFI44L & 0.92 & 7.69 & 5.88 & -1.37 \\
\hline 1.42 & 0.26 & 0.23 & -0.01 & IFIH1 & 1.93 & 3.49 & 2.47 & -0.46 \\
\hline 1.13 & 1.15 & -0.61 & -0.49 & IFIT1 & 3 & 7.95 & 3.75 & -1.34 \\
\hline 2.98 & 1.43 & 0.16 & 0.1 & IFIT2 & 269 & 6.79 & 3.85 & -0.46 \\
\hline 0.04 & 1.03 & -0.52 & -0.24 & IFIT5 & 1.81 & 3.55 & 2.5 & -0.04 \\
\hline 1.81 & 2.3 & 0.01 & -0.37 & IFITM1 & 1.77 & 6.87 & 4.99 & -0.43 \\
\hline-0.39 & 1.18 & 0.1 & -0.06 & IFITM2 & 0.46 & 3.05 & 0.9 & -1.28 \\
\hline 1.38 & 0.7 & 0.31 & -0.9 & ISG20 & 2.62 & 5.36 & 4.61 & -1.03 \\
\hline 1.85 & -0.23 & -0.92 & -0.65 & ISG20L2 & 1.34 & -0.2 & 0.05 & 0.31 \\
\hline 0.7 & 1.77 & 0.04 & 0.09 & MX1 & 1.22 & 5.81 & 3.88 & -0.92 \\
\hline 3.61 & 2.9 & 0.59 & 0.07 & MX2 & 0.26 & 3.83 & 1.16 & -0.96 \\
\hline-2.39 & -0.74 & -0.66 & -0.44 & CXCL1 & -1.2 & -0.87 & -0.39 & -1.53 \\
\hline-2.36 & -0.31 & -0.38 & -1.27 & CXCL2 & -1.4 & -0.94 & -1.65 & -3.09 \\
\hline-4.68 & -0.77 & -1.28 & -1.68 & CXCL3 & -2.16 & -0.75 & -1.46 & -2.03 \\
\hline-1.98 & 0.2 & -0.16 & -0.17 & CXCL5 & 0.08 & -0.89 & -0.7 & -0.84 \\
\hline-0.28 & -0.4 & -0.73 & -0.58 & CXCL6 & -0.12 & -0.31 & -0.16 & -0.16 \\
\hline 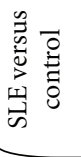 & 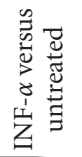 & 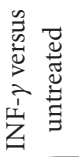 & 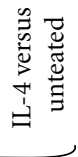 & & 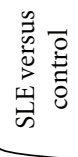 & 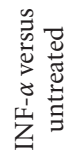 & 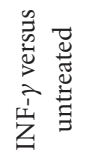 & 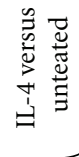 \\
\hline & & & & & & & & \\
\hline
\end{tabular}

(a)

H4ac Expression

Interferon including genes $(n=17)$

\begin{tabular}{ccccccccc}
\hline & SLE & AIFN & GIFN & IL4 & SLE & AIFN & GIFN & IL4 \\
\hline Mean & 1.1 & 1.09 & 0.25 & $2-0.21$ & 1.35 & 4.45 & 3.13 & $2-0.53$ \\
$P$ value & $23.1 e-3$ & $22.5 e-4$ & $21.6 e-1$ & $28.3 e-2$ & $25.2 e-5$ & $22.4 e-6$ & $25 e-6$ & $22.7 e-3$ \\
\hline
\end{tabular}

CXCL genes $(n=5)$, located within Chr4 74.9-75.2 Mb region

\begin{tabular}{lcccccccc}
\hline & SLE & AIFN & GIFN & IL4 & SLE & AIFN & GIFN & IL4 \\
\hline Mean & $2-2.34$ & $2-0.4$ & $2-0.64$ & $2-0.83$ & $2-0.96$ & $2-0.75$ & $2-0.87$ & $2-1.53$ \\
$P$ value & $22.7 e-2$ & $28.1 e-2$ & $22.7 e-2$ & $24.8 e-2$ & $27 e-2$ & $22.8 e-3$ & $24 e-2$ & $24.2 e-2$ \\
\hline
\end{tabular}

(b)

FIGURE 5: SLE is known to be associated with increased expression of interferon-inducible genes and these genes have a strong association of H4ac and gene expression. We noted another cluster had a similarly strong association of H4ac and gene expression. The chemokine cluster was identified as having significantly decreased expression and H4ac in SLE monocytes. (a) The heatmap demonstrating the association of gene expression and H4ac. (b) The statistical relationship between the groups.

we directly examined whether gene expression and H4ac alterations in SLE monocytes could be attributed to cytokine exposure. The SLE literature is replete with studies demonstrating overexpression of a broad range of cytokines, not just type I interferons. The finding of specific features attributable to cytokine exposure would have a significant impact on the conceptualization of new treatments. A caveat of the system we used is that the cytokine-treated cells used as comparators represent an artificial in vitro system that clearly cannot replicate the complex chronic exposures seen in a disease state. Nevertheless, this study demonstrates that such attribution is possible and can be used to examine both the epigenetic changes in SLE as well as gene expression.

An underlying hypothesis is that monocytes "polarized" by the disease can contribute to ongoing inflammation or may mold the end organ involvement. Supporting this is the finding that in murine models of SLE as well as human disease, macrophage infiltration into the kidney correlates with the severity of the renal disease and the prognosis [27]. Aberrant regulation of chemokines, as demonstrated in this study, would be predicted to alter migration and potentially alter disease manifestations. If some of these alterations can 

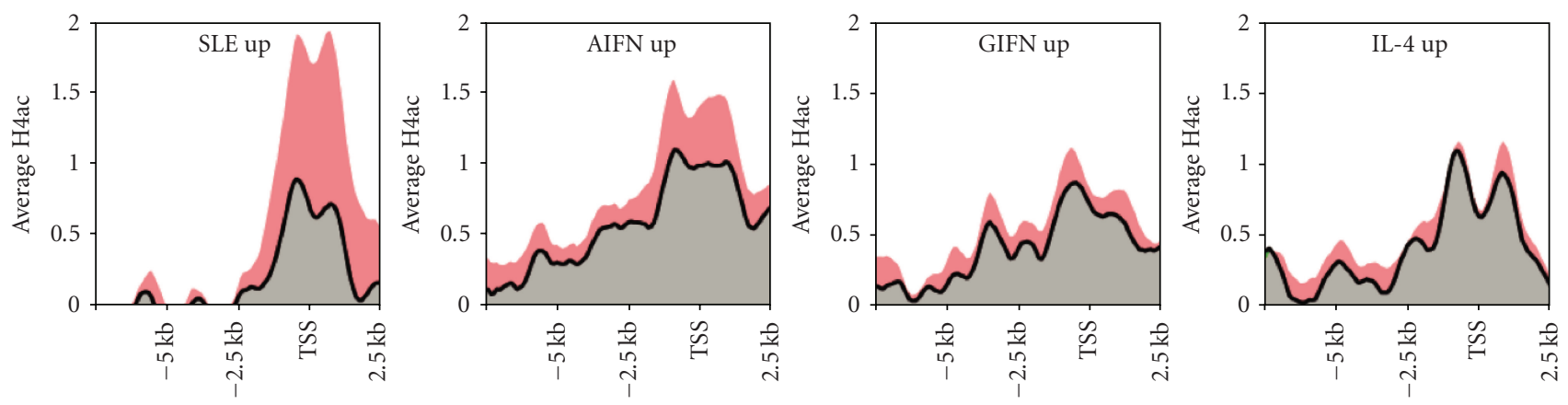

(a)
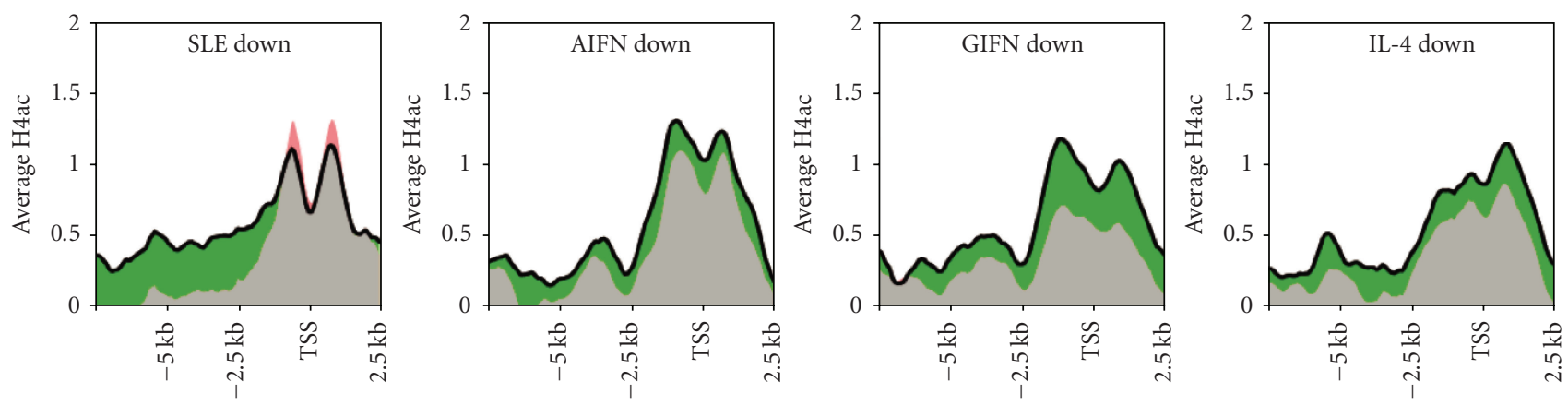

(b)

FIGURE 6: The change in gene expression in SLE or cytokine-treated samples was matched by H4ac changes in the same samples. (a) Upregulated genes seen in SLE or after cytokine treatment were examined for H4ac content. The top 200 genes with the highest expression change caused by SLE or cytokines, as was identified by previous analysis were included. (b) Down-regulated genes seen in SLE or after cytokine treatment were examined for $\mathrm{H} 4 \mathrm{ac}$ content. The 200 genes most down-regulated were examined. The black contour indicates the average H4ac in control samples and the colored regions correspond to the amount of H4ac increase (red) or decrease (green) in SLE or cytokine-treated samples.

TABLE 3: Concordance between gene expression and H4ac content.

\begin{tabular}{|c|c|c|c|c|c|c|}
\hline \multirow{2}{*}{ Group 1} & \multirow{2}{*}{ Group 0} & \multirow{2}{*}{ Correlation (r) } & \multicolumn{3}{|c|}{ Top 200 overlap* } & \multirow[b]{2}{*}{ Odds Ratio (down) } \\
\hline & & & Num_gene (up) & Odds Ratio (up) & Num_gene (down) & \\
\hline Healthy & GST & 0.39 & 8 & 1.99 & 17 & 4.65 \\
\hline SLE & GST & 0.44 & 10 & 2.54 & 24 & 7.11 \\
\hline NoRx & GST & 0.44 & 7 & 1.72 & 29 & 9.10 \\
\hline AIFN & GST & 0.45 & 10 & 2.54 & 26 & 7.88 \\
\hline GIFN & GST & 0.44 & 6 & 1.46 & 26 & 7.88 \\
\hline IL4 & GST & 0.43 & 9 & 2.26 & 31 & 9.96 \\
\hline SLE & Healthy & 0.21 & 13 & 3.41 & 22 & 6.37 \\
\hline AIFN & NoRx & 0.23 & 49 & 19.76 & 10 & 2.54 \\
\hline GIFN & NoRx & 0.19 & 34 & 11.32 & 19 & 5.32 \\
\hline IL4 & NoRx & 0.14 & 18 & 4.98 & 23 & 6.73 \\
\hline
\end{tabular}

be traced to a specific signaling pathway, a novel therapeutic target would be identified.

This study examined a specific cell type in which dysfunction has been well characterized in humans. Murine lupus models also exhibit aberrant monocyte function, suggesting it is a consistent feature of the disease. Both monocyte uptake of apoptotic cells and DNA are abnormal [90-92]. Indeed, monocyte apoptosis itself may contribute to the disease process [93]. Many SLE murine models exhibit a monocytosis, and the monocytes may amplify the inflammatory process [94-97]. In MRL/lpr mice, macrophage expression of $\gamma \mathrm{IFN}$ is required for the expression of the renal disease [98]. Additional studies demonstrated that engagement of TLR7 aggravated renal disease, characterized by infiltration of monocytes [98, 99]. In fact, inhibition of macrophage recruitment into the kidney, markedly attenuated the phenotype in MRL/lpr mice [100]. In the NZB $\times \mathrm{NZW}$ system, signaling in myeloid cells through $\mathrm{Fc} \gamma \mathrm{R}$ is critical to the inflammatory process and macrophages are critical for anti-dsDNA production 
$[101,102]$. The SLE3 locus in the NZM2410 strain, derived from NZB $\times$ NZW, appears to confer susceptibility to lupus by driving increased macrophage costimulatory activity [103, 104]. A potential role for monocytes in these models is via the inflammatory cytokines produced by monocytes and macrophages as was demonstrated in the MRL/lpr system $[98,99]$.

This study provides a potential explanation for the persistent monocyte dysfunction seen in both human SLE patients and in murine models. The effect of cytokines can induce changes in the epigenome and persistence of these changes could lead to durably altered gene expression which in turn could underlie many of the aberrant functions. There were many other effects that did not trace to the three cytokines used in this study. Potential caveats include the short exposure to cytokines in our model system, the effects from other cytokines or stimuli and the potential for the cells to have an aberrant differentiation pathway in the presence of active SLE.

This study hypothesized that many of the changes in both gene expression and H4ac would be attributable to type I interferons since their effects have been well characterized in SLE $[16,51,105]$. Indeed, many effects in gene expression and $\mathrm{H} 4 \mathrm{ac}$ could be traced to $\alpha \mathrm{IFN}$, although $\gamma$ IFN led to similar changes. There are several lines of evidence suggesting that monocytes have been molded by a complex set of exposures. Our cytokine attribution found that the interferon-responsive genes cluster was upregulated $36.3 \%$ in SLE monocytes, thus leaving a significant gene set unexplained by interferon exposure. The association was even less robust for $\mathrm{H} 4 \mathrm{ac}$. The finding that $\mathrm{H} 4$ acetylation was globally increased and this increase appeared to map to TFBSs suggests a globally altered epigenome with a complex etiology. Therefore, monocytes are significantly impacted by both $\alpha$ IFN and $\gamma$ IFN exposure, however, our data suggest that additional cytokines and other exposures contribute to the aberrant monocyte behavior observed in SLE patients.

\section{Acknowledgment}

This work was supported in part by NIH R01 AI 0511323 and R01 ES 017627. The authors would like to thank Dr. Micheal Petzl.

\section{References}

[1] E. Robak, A. Sysa-Jedrzejewska, B. Dziankowska, D. Torzecka, K. Chojnowski, and T. Robak, "Association of interferon $\gamma$, tumor necrosis factor $\alpha$ and interleukin 6 serum levels with systemic lupus erythematosus activity," Archivum Immunologiae et Therapiae Experimentalis, vol. 46, no. 6, pp. 375-380, 1998.

[2] E. Waszczykowska, E. Robak, A. Wozniacka, J. Narbutt, J. D. Torzecka, and A. Sysa-Jedrzejowska, "Estimation of SLE activity based on the serum level of chosen cytokines and superoxide radical generation," Mediators of Inflammation, vol. 8, no. 2, pp. 93-100, 1999.

[3] E. M. Davas, A. Tsirogianni, I. Kappou, D. Karamitsos, I. Economidou, and P. C. Dantis, "Serum IL-6, TNF $\alpha$, p55
$\operatorname{srTNF} \alpha, \mathrm{p} 75 \operatorname{srTNF} \alpha$, srIL-2 $\alpha$ levels and disease activity in systemic lupus erythematosus," Clinical Rheumatology, vol. 18, no. 1, pp. 17-22, 1999.

[4] M. Linker-Israeli, R. J. Deans, D. J. Wallace, J. Prehn, T. OzeriChen, and J. R. Klinenberg, "Elevated levels of endogenous IL-6 in systemic lupus erythematosus. A putative role in pathogenesis," Journal of Immunology, vol. 147, no. 1, pp. 117-123, 1991.

[5] C. K. Wong, L. C. W. Lit, L. S. Tam, E. K. M. Li, P. T. Y. Wong, and C. W. K. Lam, "Hyperproduction of IL-23 and IL-17 in patients with systemic lupus erythematosus: implications for Th17-mediated inflammation in auto-immunity," Clinical Immunology, vol. 127, no. 3, pp. 385-393, 2008.

[6] C. K. Wong, C. Y. Ho, E. K. Li, and C. W. K. Lam, "Elevation of proinflammatory cytokine (IL-18, IL-17, IL-12) and Th2 cytokine (IL-4) concentrations in patients with systemic lupus erythematosus," Lupus, vol. 9, no. 8, pp. 589-593, 2000.

[7] M. Akahoshi, H. Nakashima, Y. Tanaka et al., "Th1/Th2 balance of peripheral $\mathrm{T}$ helper cells in systemic lupus erythematosus," Arthritis and Rheumatism, vol. 42, no. 8, pp. 1644-1648, 1999.

[8] E. Hagiwara, M. F. Gourley, S. Lee, and D. M. Klinman, "Disease severity in patients with systemic lupus erythematosus correlates with an increased ratio of interleukin10 :interferon- $\gamma$-secreting cells in the peripheral blood," Arthritis and Rheumatism, vol. 39, no. 3, pp. 379-385, 1996.

[9] A. Csiszár, GY. Nagy, P. Gergely, T. Pozsonyi, and É. Pócsik, "Increased interferon-gamma (IFN- $\gamma$ ), IL-10 and decreased IL-4 mRNA expression in peripheral blood mononuclear cells (PBMC) from patients with systemic lupus erythematosus (SLE)," Clinical and Experimental Immunology, vol. 122, no. 3, pp. 464-470, 2000.

[10] M. R. Amel-Kashipaz, M. L. Huggins, P. Lanyon, A. Robins, I. Todd, and R. J. Powell, "Quantitative and qualitative analysis of the balance between type 1 and type 2 cytokine-producing $\mathrm{CD}^{-}$and $\mathrm{CD} 8^{+} \mathrm{T}$ cells in systemic lupus erythematosus," Journal of Autoimmunity, vol. 17, no. 2, pp. 155-163, 2001.

[11] A. E. Mongan, S. Ramdahin, and R. J. Warrington, "Interleukin-10 response abnormalities in systemic lupus erythematosus," Scandinavian Journal of Immunology, vol. 46, no. 4, pp. 406-412, 1997.

[12] J. C. Crispín, M. Oukka, G. Bayliss et al., "Expanded double negative $\mathrm{T}$ cells in patients with systemic lupus erythematosus produce IL-17 and infiltrate the kidneys," Journal of Immunology, vol. 181, no. 12, pp. 8761-8766, 2008.

[13] D. A. Horwitz, J. D. Gray, S. C. Behrendsen et al., "Decreased production of interleukin-12 and other Th1-type cytokines in patients with recent-onset systemic lupus erythematosus," Arthritis and Rheumatism, vol. 41, no. 5, pp. 838-844, 1998.

[14] D.-J. Min, M.-L. Cho, C.-S. Cho et al., "Decreased production of interleukin-12 and interferon- $\gamma$ is associated with renal involvement in systemic lupus erythematosus," Scandinavian Journal of Rheumatology, vol. 30, no. 3, pp. 159-163, 2001.

[15] M. C. Dall'Era, P. M. Cardarelli, B. T. Preston, A. Witte, and J. C. Davis Jr., "Type I interferon correlates with serological and clinical manifestations of SLE," Annals of the Rheumatic Diseases, vol. 64, no. 12, pp. 1692-1697, 2005.

[16] L. Bennett, A. K. Palucka, E. Arce et al., "Interferon and granulopoiesis signatures in systemic lupus erythematosus blood," Journal of Experimental Medicine, vol. 197, no. 6, pp. 711-723, 2003. 
[17] A. A. Bengtsson, G. Sturfelt, L. Truedsson et al., "Activation of type I interferon system in systemic lupus erythematosus correlates with disease activity but not with antiretroviral antibodies," Lupus, vol. 9, no. 9, pp. 664-671, 2000.

[18] J. Banchereau and V. Pascual, "Type I interferon in systemic lupus erythematosus and other autoimmune diseases," Immunity, vol. 25, no. 3, pp. 383-392, 2006.

[19] E. C. Baechler, F. M. Batliwalla, G. Karypis et al., "Interferoninducible gene expression signature in peripheral blood cells of patients with severe lupus," Proceedings of the National Academy of Sciences of the United States of America, vol. 100, no. 5, pp. 2610-2615, 2003.

[20] Y. Yao, L. Richman, B. W. Higgs et al., "Neutralization of interferon- $\alpha / \beta$-inducible genes and downstream effect in a phase I trial of an anti-interferon- $\alpha$ monoclonal antibody in systemic lupus erythematosus," Arthritis and Rheumatism, vol. 60, no. 6, pp. 1785-1796, 2009.

[21] V. Rus, S. P. Atamas, V. Shustova et al., "Expression of cytokine- and chemokine-related genes in peripheral blood mononuclear cells from lupus patients by cDNA array," Clinical Immunology, vol. 102, no. 3, pp. 283-290, 2002.

[22] H. Kaneko, H. Ogasawara, T. Naito et al., "Circulating levels of $\beta$-chemokines in systemic lupus erythematosus," Journal of Rheumatology, vol. 26, no. 3, pp. 568-573, 1999.

[23] T. Wu, C. Xie, H. W. Wang et al., "Elevated urinary VCAM1, P-selectin, soluble TNF receptor-1, and CXC chemokine ligand 16 in multiple murine lupus strains and human lupus nephritis," Journal of Immunology, vol. 179, no. 10, pp. 7166 7175, 2007.

[24] G. M. Ferri, A. Gigante, F. Ferri et al., "Urine chemokines: biomarkers of human lupus nephritis?" European Review for Medical and Pharmacological Sciences, vol. 11, no. 3, pp. 171178, 2007.

[25] D. Schübeler, D. M. MacAlpine, D. Scalzo et al., "The histone modification pattern of active genes revealed through genome-wide chromatin analysis of a higher eukaryote," Genes and Development, vol. 18, no. 11, pp. 1263-1271, 2004.

[26] T. Agalioti, G. Chen, and D. Thanos, "Deciphering the transcriptional histone acetylation code for a human gene," Cell, vol. 111, no. 3, pp. 381-392, 2002.

[27] G. S. Hill, M. Delahousse, D. Nochy et al., "Predictive power of the second renal biopsy in lupus nephritis: significance of macrophages," Kidney International, vol. 59, no. 1, pp. 304316, 2001.

[28] S. Yoshimoto, K. Nakatani, M. Iwano et al., "Elevated levels of fractalkine expression and accumulation of $\mathrm{CD}_{16}{ }^{+}$ monocytes in glomeruli of active lupus nephritis," American Journal of Kidney Diseases, vol. 50, no. 1, pp. 47-58, 2007.

[29] A. Foote, E. M. Briganti, Y. Kipen, L. Santos, M. Leech, and E. F. Morand, "Macrophage migration inhibitory factor in systemic lupus erythematosus," Journal of Rheumatology, vol. 31, no. 2, pp. 268-273, 2004.

[30] C. Meijer, V. Huysen, R. T. J. Smeenk, and A. J. G. Swaak, "Profiles of cytokines (TNF $\alpha$ and IL-6) and acute phase proteins (CRP and $\alpha 1 \mathrm{AG}$ ) related to the disease course in patients with systemic lupus erythematosus," Lupus, vol. 2, no. 6, pp. 359-365, 1993.

[31] D. A. Horwitz, H. Wang, and J. D. Gray, "Cytokine gene profile in circulating blood mononuclear cells from patients with systemic lupus erythematosus: increased interleukin-2 but not interleukin-4 mRNA," Lupus, vol. 3, no. 5, pp. 423 428, 1994.
[32] S. Pégorier, D. Stengel, H. Durand, M. Croset, and E. Ninio, "Oxidized phospholipid: POVPC binds to plateletactivating-factor receptor on human macrophages. Implications in atherosclerosis," Atherosclerosis, vol. 188, no. 2, pp. 433-443, 2006.

[33] M. F. Denny, S. Thacker, H. Mehta et al., "Interferon$\alpha$ promotes abnormal vasculogenesis in lupus: a potential pathway for premature atherosclerosis," Blood, vol. 110, no. 8, pp. 2907-2915, 2007.

[34] Y. Asanuma, A. Oeser, A. K. Shintani et al., "Premature coronary-artery atherosclerosis in systemic lupus erythematosus," New England Journal of Medicine, vol. 349, no. 25, pp. 2407-2415, 2003.

[35] P. Barath, M. C. Fishbein, J. Cao, J. Berenson, R. H. Helfant, and J. S. Forrester, "Detection and localization of tumor necrosis factor in human atheroma," American Journal of Cardiology, vol. 65, no. 5, pp. 297-302, 1990.

[36] Y. Shoshan, I. Shapira, E. Toubi, I. Frolkis, M. Yaron, and D. Mevorach, "Accelerated Fas-mediated apoptosis of monocytes and maturing macrophages from patients with systemic lupus erythematosus: relevance to in vitro impairment of interaction with iC3b-opsonized apoptotic cells," Journal of Immunology, vol. 167, no. 10, pp. 5963-5969, 2001.

[37] M. Köller, B. Zwölfer, G. Steiner, J. S. Smolen, and C. Scheinecker, "Phenotypic and functional deficiencies of monocyte-derived dendritic cells in systemic lupus erythematosus (SLE) patients," International Immunology, vol. 16, no. 11, pp. 1595-1604, 2004.

[38] P. J. Russell and A. D. Steinberg, "Studies of peritoneal macrophage function in mice with systemic lupus erythematosus: depressed phagocytosis of opsonized sheep erythrocytes in vitro," Clinical Immunology and Immunopathology, vol. 27, no. 3, pp. 387-402, 1983.

[39] A. P. Dang-Vu, D. S. Pisetsky, and J. B. Weinberg, "Functional alterations of macrophages in autoimmune MRL-lpr/lpr mice," Journal of Immunology, vol. 138, no. 6, pp. 1757-1761, 1987.

[40] C. M. Brozek, C. L. Hoffman, S. M. Savage, and R. P. Searles, "Systemic lupus erythematosus sera inhibit antigen presentation by macrophages to T cells," Clinical Immunology and Immunopathology, vol. 46, no. 2, pp. 299-313, 1988.

[41] X. Lopez-Karpovitch, M. Cardiel, R. Cardenas, J. Piedras, and D. Alarcon-Segovia, "Circulating colony-forming units of granulocytes and monocytes/macrophages in systemic lupus erythematosus," Clinical and Experimental Immunology, vol. 77, no. 1, pp. 43-46, 1989.

[42] D. Zippel, V. Lackovic, D. Kociskova, J. Rovensky, L. Borecky, and A. Stelzner, "Abnormal macrophages and NK cell cytotoxicity in human systemic lupus erythematosus and the role of interferon and serum factors," Acta Virologica, vol. 33, no. 5, pp. 447-453, 1989.

[43] A. A. Bengtsson, G. Sturfelt, B. Gullstrand, and L. Truedsson, "Induction of apoptosis in monocytes and lymphocytes by serum from patients with systemic lupus erythematosusan additional mechanism to increased autoantigen load?" Clinical and Experimental Immunology, vol. 135, no. 3, pp. 535-543, 2004.

[44] J. Bayry, S. Lacroix-Desmazes, S. Delignat et al., "Intravenous immunoglobulin abrogates dendritic cell differentiation induced by interferon- $\alpha$ present in serum from patients with systemic lupus erythematosus," Arthritis and Rheumatism, vol. 48, no. 12, pp. 3497-3502, 2003. 
[45] N. Figueroa-Vega, G. Galindo-Rodríguez, S. Bajaña et al., "Phenotypic analysis of IL-10-treated, monocyte-derived dendritic cells in patients with systemic lupus erythematosus," Scandinavian Journal of Immunology, vol. 64, no. 6, pp. 668-676, 2006.

[46] I. Baumann, W. Kolowos, R. E. Voll et al., "Impaired uptake of apoptotic cells into tingible body macrophages in germinal centers of patients with systemic lupus erythematosus," Arthritis and Rheumatism, vol. 46, no. 1, pp. 191-201, 2002.

[47] Y. Ren, J. Tang, M. Y. Mok, A. W. K. Chan, A. Wu, and C. S. Lau, "Increased apoptotic neutrophils and macrophages and impaired macrophage phagocytic clearance of apoptotic neutrophils in systemic lupus erythematosus," Arthritis and Rheumatism, vol. 48, no. 10, pp. 2888-2897, 2003.

[48] M. Bijl, E. Reefman, G. Horst, P. C. Limburg, and C. G. M. Kallenberg, "Reduced uptake of apoptotic cells by macrophages in systemic lupus erythematosus: correlates with decreased serum levels of complement," Annals of the Rheumatic Diseases, vol. 65, no. 1, pp. 57-63, 2006.

[49] S. W. Tas, P. Quartier, M. Botto, and L. Fossati-Jimack, "Macrophages from patients with SLE and rheumatoid arthritis have defective adhesion in vitro, while only SLE macrophages have impaired uptake of apoptotic cells," Annals of the Rheumatic Diseases, vol. 65, no. 2, pp. 216-221, 2006.

[50] T. Kuroiwa, R. Schlimgen, G. G. Illei, and D. T. Boumpas, "Monocyte response to Th1 stimulation and effector function toward human mesangial cells are not impaired in patients with lupus nephritis," Clinical Immunology, vol. 106, no. 1, pp. 65-72, 2003.

[51] K. A. Kirou, C. Lee, S. George et al., "Coordinate overexpression of interferon- $\alpha$-induced genes in systemic lupus erythematosus," Arthritis and Rheumatism, vol. 50, no. 12, pp. 3958-3967, 2004.

[52] J. Hua, K. Kirou, C. Lee, and M. K. Crow, "Functional assay of type I interferon in systemic lupus erythematosus plasma and association with anti-RNA binding protein autoantibodies," Arthritis and Rheumatism, vol. 54, no. 6, pp. 1906-1916, 2006.

[53] O. T. Preble, R. J. Black, and R. M. Friedman, "Systemic lupus erythematosus: presence in human serum of an unusual acidlabile leukocyte interferon," Science, vol. 216, no. 4544, pp. 429-431, 1982.

[54] L.-B. Liou, "Different monocyte reaction patterns in newly diagnosed, untreated rheumatoid arthritis and lupus patients probably confer disparate C-reactive protein levels," Clinical and Experimental Rheumatology, vol. 21, no. 4, pp. 437-444, 2003.

[55] F. Steinbach, F. Henke, B. Krause, B. Thiele, G.-R. Burmester, and F. Hiepe, "Monocytes from systemic lupus erythematous patients are severely altered in phenotype and lineage flexibility," Annals of the Rheumatic Diseases, vol. 59, no. 4, pp. 283-288, 2000.

[56] R. A. Zeuner, D. M. Klinman, G. Illei et al., "Response of peripheral blood mononuclear cells from lupus patients to stimulation by CpG oligodeoxynucleotides," Rheumatology, vol. 42, no. 4, pp. 563-569, 2003.

[57] C. G. Katsiari, S.-N. C. Liossis, V. L. Souliotis, A. M. Dimopoulos, M. N. Manoussakis, and P. P. Sfikakis, "Aberrant expression of the costimulatory molecule CD40 ligand on monocytes from patients with systemic lupus erythematosus," Clinical Immunology, vol. 103, no. 1, pp. 54-62, 2002.
[58] L.-B. Liou, "Serum and in vitro production of IL-1 receptor antagonist correlate with C-reactive protein levels in newly diagnosed, untreated lupus patients," Clinical and Experimental Rheumatology, vol. 19, no. 5, pp. 515-523, 2001.

[59] M. Linker-Israeli, D. J. Wallace, J. Prehn et al., "Association of IL-6 gene alleles with systemic lupus erythematosus (SLE) and with elevated IL-6 expression," Genes and Immunity, vol. 1, no. 1, pp. 45-52, 1999.

[60] B. S. Chae and T. Y. Shin, "Immunoregulatory abnormalities of $\mathrm{T}$ cells and hyperreactivity of $\mathrm{B}$ cells in the in vitro immune response in pristane-induced lupus mice," Archives of Pharmacal Research, vol. 30, no. 2, pp. 191-198, 2007.

[61] B. M. Jones, T. Liu, and R. W. S. Wong, "Reduced in vitro production of interferon-gamma, interleukin-4 and interleukin-12 and increased production of interleukin-6, interleukin-10 and tumour necrosis factor-alpha in systemic lupus erythematosus. Weak correlations of cytokine production with disease activity," Autoimmunity, vol. 31, no. 2, pp. 117-124, 1999.

[62] J. Liu and D. Beller, "Aberrant production of IL-12 by macrophages from several autoimmune-prone mouse strains is characterized by intrinsic and unique patterns of NF- $\kappa \mathrm{B}$ expression and binding to the IL-12 p40 promoter," Journal of Immunology, vol. 169, no. 1, pp. 581-586, 2002.

[63] D. G. Alleva, S. B. Kaser, and D. I. Beller, "Intrinsic defects, in macrophage IL-12 production associated with immune dysfunction in the MRL/++ and New Zealand black/white F1 lupus-prone mice and the Leishmania major-susceptible BALB/c strain," Journal of Immunology, vol. 161, no. 12, pp. 6878-6884, 1998.

[64] T. F. Liu and B. M. Jones, "Impaired production of IL-12 in systemic lupus erythematosus. I. Excessive production of IL10 suppresses production of IL-12 by monocytes," Cytokine, vol. 10, no. 2, pp. 140-147, 1998.

[65] H. Yu, S. Zhu, B. Zhou, H. Xue, and J.-D. J. Han, "Inferring causal relationships among different histone modifications and gene expression," Genome Research, vol. 18, no. 8, pp. 1314-1324, 2008.

[66] B. E. Bernstein, M. Kamal, K. Lindblad-Toh et al., "Genomic maps and comparative analysis of histone modifications in human and mouse," Cell, vol. 120, no. 2, pp. 169-181, 2005.

[67] T.-Y. Roh, G. Wei, C. M. Farrell, and K. Zhao, "Genomewide prediction of conserved and nonconserved enhancers by histone acetylation patterns," Genome Research, vol. 17, no. 1, pp. 74-81, 2007.

[68] Z. Zhang, L. Song, K. Maurer, M. A. Petri, and K. E. Sullivan, "Global H4 acetylation analysis by ChIP-chip in systemic lupus erythematosus monocytes," Genes and Immunity, 2009.

[69] S. Garrett, K. Dietzmann-Maurer, L. Song, and K. E. Sullivan, "Polarization of primary human monocytes by IFN- $\gamma$ induces chromatin changes and recruits RNA pol II to the TNF- $\alpha$ promoter," Journal of Immunology, vol. 180, no. 8, pp. 5257-5266, 2008.

[70] J. Y. Lee, N. A. Kim, A. Sanford, and K. E. Sullivan, "Histone acetylation and chromatin conformation are regulated separately at the TNF- $\alpha$ promoter in monocytes and macrophages," Journal of Leukocyte Biology, vol. 73, no. 6, pp. 862-871, 2003.

[71] G. Dennis Jr., B. T. Sherman, D. A. Hosack et al., "DAVID: database for annotation, visualization, and integrated discovery," Genome Biology, vol. 4, no. 5, p. P3, 2003.

[72] J. Hutcheson, J. C. Scatizzi, A. M. Siddiqui et al., "Combined deficiency of proapoptotic regulators bim and fas results in 
the early onset of systemic autoimmunity," Immunity, vol. 28, no. 2, pp. 206-217, 2008.

[73] K. E. Sullivan, A. Suriano, K. Dietzmann, J. Lin, D. Goldman, and M. A. Petri, "The TNF $\alpha$ locus is altered in monocytes from patients with systemic lupus erythematosus," Clinical Immunology, vol. 123, no. 1, pp. 74-81, 2007.

[74] A. L. Clayton, C. A. Hazzalin, and L. C. Mahadevan, "Enhanced histone acetylation and transcription: a dynamic perspective," Molecular Cell, vol. 23, no. 3, pp. 289-296, 2006.

[75] E. J. Bellefroid, D. A. Poncelet, P. J. Lecocq, O. Revelant, and J. A. Martial, "The evolutionarily conserved Kruppelassociated box domain defines a subfamily of eukaryotic multifingered proteins," Proceedings of the National Academy of Sciences of the United States of America, vol. 88, no. 9, pp. 3608-3612, 1991.

[76] H. Haghnegahdar, J. Du, D. Wang et al., "The tumorigenic and angiogenic effects of MGSA/GRO proteins in melanoma," Journal of Leukocyte Biology, vol. 67, no. 1, pp. 53-62, 2000.

[77] L. M. Pelus and S. Fukuda, "Peripheral blood stem cell mobilization: the CXCR2 ligand GRO $\beta$ rapidly mobilizes hematopoietic stem cells with enhanced engraftment properties," Experimental Hematology, vol. 34, no. 8, pp. 1010-1020, 2006.

[78] D. F. Smith, E. Galkina, K. Ley, and Y. Huo, "GRO family chemokines are specialized for monocyte arrest from flow," American Journal of Physiology, vol. 289, no. 5, pp. H1976H1984, 2005.

[79] M.-S. Chang, J. McNinch, R. Basu, and S. Simonet, "Cloning and characterization of the human neutrophil-activating peptide (ENA-78) gene," Journal of Biological Chemistry, vol. 269, no. 41, pp. 25277-25282, 1994.

[80] A. Wuyts, N. Van Osselaer, A. Haelens et al., "Characterization of synthetic human granulocyte chemotactic protein 2: usage of chemokine receptors CXCR1 and CXCR2 and in vivo inflammatory properties," Biochemistry, vol. 36, no. 9, pp. 2716-2723, 1997.

[81] B. Richardson, L. Scheinbart, J. Strahler, L. Gross, S. Hanash, and M. Johnson, "Evidence for impaired T cell DNA methylation in systemic lupus erythematosus and rheumatoid arthritis," Arthritis and Rheumatism, vol. 33, no. 11, pp. 16651673, 1990.

[82] J. Quddus, K. J. Johnson, J. Gavalchin et al., "Treating activated CD4+ $\mathrm{T}$ cells with either of two distinct DNA methyltransferase inhibitors, 5-azacytidine or procainamide, is sufficient to cause a lupus-like disease in syngeneic mice," Journal of Clinical Investigation, vol. 92, no. 1, pp. 38-53, 1993.

[83] C. Deng, Q. Lu, Z. Zhang et al., "Hydralazine may induce autoimmunity by inhibiting extracellular signal-regulated kinase pathway signaling," Arthritis and Rheumatism, vol. 48, no. 3, pp. 746-756, 2003.

[84] L. S. Scheinbart, M. A. Johnson, L. A. Gross, S. R. Edelstein, and B. C. Richardson, "Procainamide inhibits DNA methyltransferase in a human T cell line," Journal of Rheumatology, vol. 18, no. 4, pp. 530-534, 1991.

[85] M. J. Kaplan, Q. Lu, A. Wu, J. Attwood, and B. Richardson, "Demethylation of promoter regulatory elements contributes to perforin overexpression in $\mathrm{CD} 4^{+}$lupus T cells," Journal of Immunology, vol. 172, no. 6, pp. 3652-3661, 2004.

[86] R. Yung, D. Powers, K. Johnson et al., "Mechanisms of drug-induced lupus II. T cells overexpressing lymphocyte function-associated antigen 1 become autoreactive and cause a lupuslike disease in syngeneic mice," Journal of Clinical Investigation, vol. 97, no. 12, pp. 2866-2871, 1996.

[87] B. C. Richardson, J. R. Strahler, T. S. Pivirotto et al., "Phenotypic and functional similarities between 5-azacytidinetreated $\mathrm{T}$ cells and a $\mathrm{T}$ cell subset in patients with active systemic lupus erythematosus," Arthritis and Rheumatism, vol. 35, no. 6, pp. 647-662, 1992.

[88] C. M. Reilly, N. Mishra, J. M. Miller et al., "Modulation of renal disease in MRL/lpr mice by suberoylanilide hydroxamic acid," Journal of Immunology, vol. 173, no. 6, pp. 4171-4178, 2004.

[89] S. Skov, K. Rieneck, L. F. Bovin et al., "Histone deacetylase inhibitors: a new class of immunosuppressors targeting a novel signal pathway essential for CD154 expression," Blood, vol. 101, no. 4, pp. 1430-1438, 2003.

[90] Y. Ogawa, T. Yoshinaga, K. Yasuda, M. Nishikawa, and Y. Takakura, "The uptake and degradation of DNA is impaired in macrophages and dendritic cells from NZB/W F1 mice," Immunology Letters, vol. 101, no. 1, pp. 32-40, 2005.

[91] R. Licht, J. W. C. Dieker, C. W. M. Jacobs, W. J. M. Tax, and J. H. M. Berden, "Decreased phagocytosis of apoptotic cells in diseased SLE mice," Journal of Autoimmunity, vol. 22, no. 2, pp. 139-145, 2004.

[92] F. Carlucci, J. Cortes-Hernandez, L. Fossati-Jimack et al., "Genetic dissection of spontaneous autoimmunity driven by 129-derived chromosome 1 loci when expressed on C57BL/6 mice," Journal of Immunology, vol. 178, no. 4, pp. 2352-2360, 2007.

[93] M. F. Denny, P. Chandaroy, P. D. Killen et al., "Accelerated macrophage apoptosis induces autoantibody formation and organ damage in systemic lupus erythematosus," Journal of Immunology, vol. 176, no. 4, pp. 2095-2104, 2006.

[94] T. A. Davis and G. Lennon, "Mice with a regenerative wound healing capacity and an SLE autoimmune phenotype contain elevated numbers of circulating and marrow-derived macrophage progenitor cells," Blood Cells, Molecules, and Diseases, vol. 34, no. 1, pp. 17-25, 2005.

[95] G. Vieten, M. R. Hadam, H. De Boer, A. Olp, M. Fricke, and K. Hartung, "Expanded macrophage precursor populations in BXSB mice: possible reason for the increasing monocytosis in male mice," Clinical Immunology and Immunopathology, vol. 65, no. 3, pp. 212-218, 1992.

[96] M. Muller, A. Emmendorffer, and M.-L. LohmannMatthes, "Expansion and high proliferative potential of the macrophage system throughout life time of lupus-prone NZB/W and MRL lpr/lpr mice. Lack of down-regulation of extramedullar macrophage proliferation in the postnatal period," European Journal of Immunology, vol. 21, no. 9, pp. 2211-2217, 1991.

[97] H. Amano, E. Amano, M.-L. Santiago-Raber et al., "Selective expansion of a monocyte subset expressing the CD11c dendritic cell marker in the Yaa model of systemic lupus erythematosus," Arthritis and Rheumatism, vol. 52, no. 9, pp. 2790-2798, 2005.

[98] C. E. Carvalho-Pinto, M. I. García, M. Mellado et al., "Autocrine production of IFN- $\gamma$ by macrophages controls their recruitment to kidney and the development of glomerulonephritis in MRL/lpr mice," Journal of Immunology, vol. 169, no. 2, pp. 1058-1067, 2002.

[99] R. D. Pawar, P. S. Patole, D. Zecher et al., "Toll-like receptor-7 modulates immune complex glomerulonephritis," Journal of the American Society of Nephrology, vol. 17, no. 1, pp. 141149, 2006. 
[100] A. Y. Hoi, M. J. Hickey, P. Hall et al., "Macrophage migration inhibitory factor deficiency attenuates macrophage recruitment, glomerulonephritis, and lethality in MRL/lpr mice," Journal of Immunology, vol. 177, no. 8, pp. 5687-5696, 2006.

[101] A. Bergtold, A. Gavhane, V. D'Agati, M. Madaio, and R. Clynes, "FcR-bearing myeloid cells are responsible for triggering murine lupus nephritis," Journal of Immunology, vol. 177, no. 10, pp. 7287-7295, 2006.

[102] M. E. Alarcon-Riquelme, G. Moller, and C. Fernandez, "Macrophage depletion decreases IgG anti-DNA in cultures from $(\mathrm{NZB} \times \mathrm{NZW}) \mathrm{F} 1$ spleen cells by eliminating the main source of IL-6," Clinical and Experimental Immunology, vol. 91, no. 2, pp. 220-225, 1993.

[103] E. S. Sobel, L. Morel, R. Baert, C. Mohan, J. Schiffenbauer, and E. K. Wakeland, "Genetic dissection of systemic lupus erythematosus pathogenesis: evidence for functional expression of Sle3/5 by non-T cells," Journal of Immunology, vol. 169, no. 7, pp. 4025-4032, 2002.

[104] J. Zhu, X. Liu, C. Xie et al., "T cell hyperactivity in lupus as a consequence of hyperstimulatory antigen-presenting cells," Journal of Clinical Investigation, vol. 115, no. 7, pp. 18691878, 2005.

[105] E. C. Baechler, J. W. Bauer, C. A. Slattery et al., "An interferon signature in the peripheral blood of dermatomyositis patients is associated with disease activity," Molecular Medicine, vol. 13, no. 1-2, pp. 59-68, 2007. 


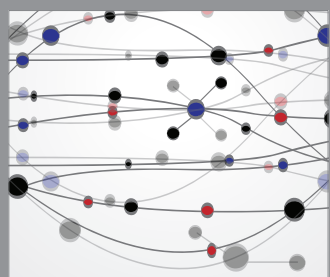

The Scientific World Journal
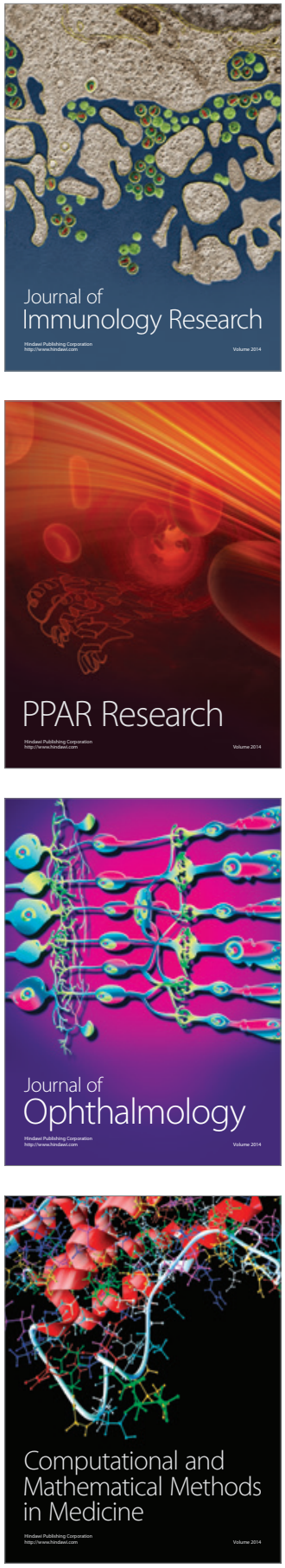

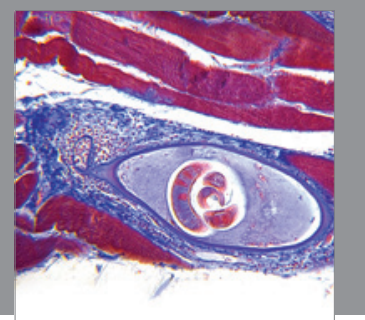

Gastroenterology

Research and Practice
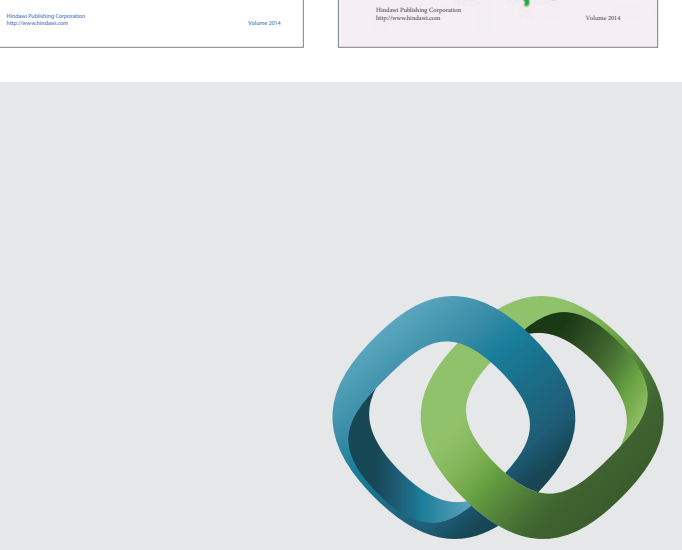

\section{Hindawi}

Submit your manuscripts at

http://www.hindawi.com
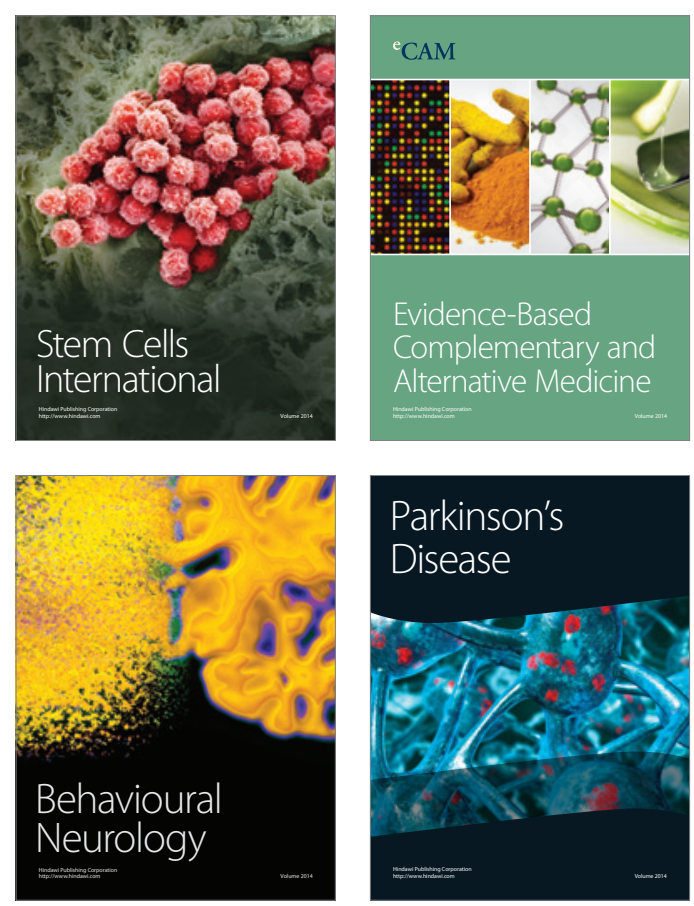

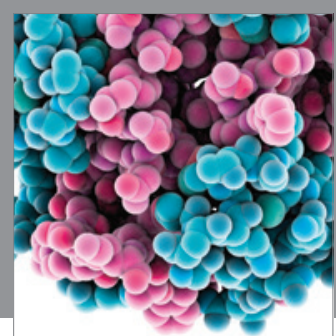

Journal of
Diabetes Research

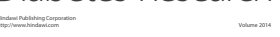

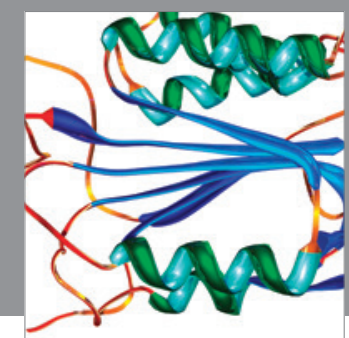

Disease Markers
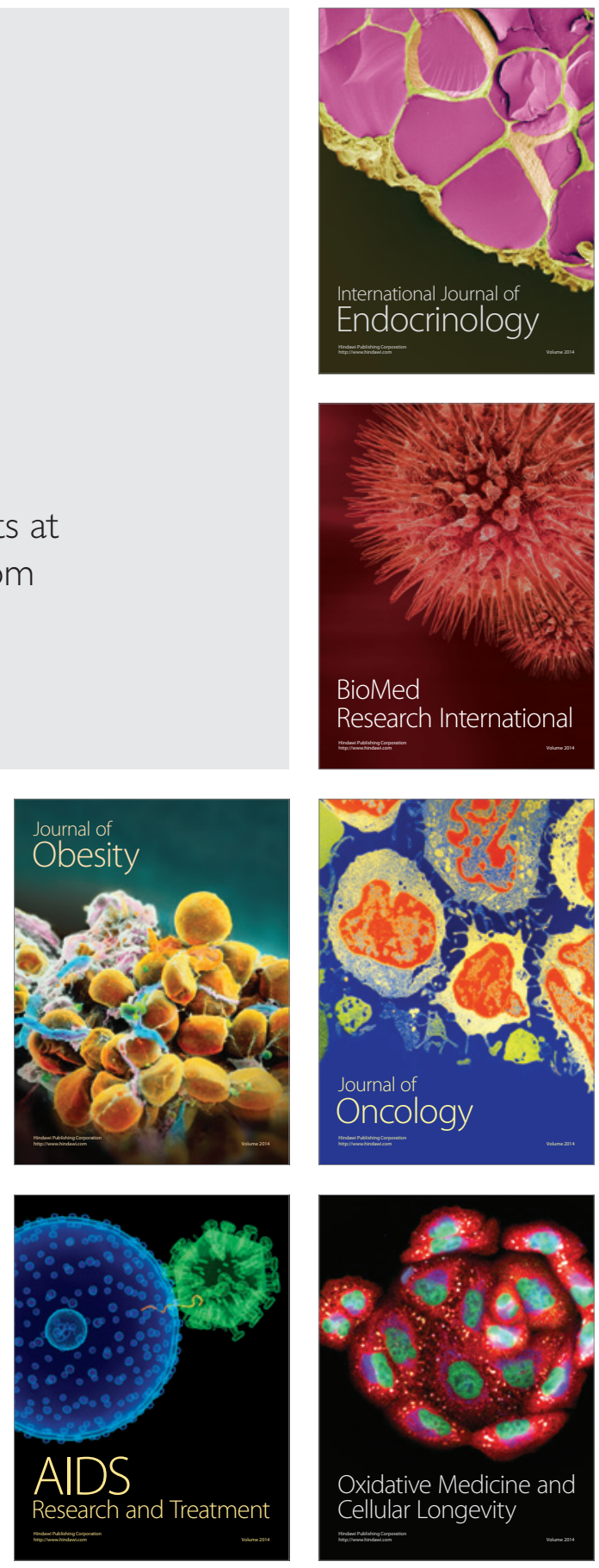